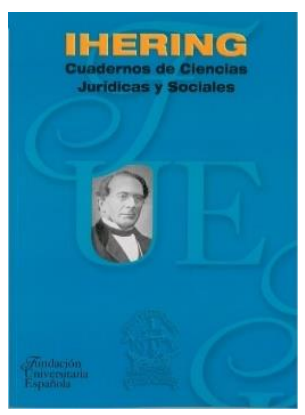

(c) $($ ) (9)
Ihering. Cuadernos de Ciencias Jurídicas y Sociales

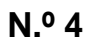

Año: 2021

Publicación del SEMINARIO DE ESTUDIOS EUROPEOS "DIEGO DE MENDOZA" de la

Fundación Universitaria Española

e-ISSN: 2660-552X

DOI: https://doi.org/10.51743/ihering. 106

Recibido: 10-03-2021 | Revisado: 24-03-2021

|Aceptado: 05-04-2021 | Publicado: 23-12-2021

\title{
LA EVOLUCIÓN HISTÓRICA DE LA IGUALDAD DE GÉNERO DESDE EL PRISMA DE LA ORGANIZACIÓN DE NACIONES UNIDAS
}

THE HISTORICAL EVOLUTION OF GENDER EQUALITY FROM THE PRISM OF THE UNITED NATIONS ORGANIZATION

Tiffany Sánchez-Cabezudo Rina

Dialnet

(Universidad Rey Juan Carlos)

\section{Resumen}

El presente trabajo se ha centrado en sintetizar la evolución de la igualdad de género en el ámbito de la Organización de Naciones Unidas, diferenciando varias etapas. En cada una de ellas se ha descrito cuáles han sido las acciones más relevantes de la ONU para luchar contra la discriminación de género, identificando a la misma vez cuál era la situación en España. Antes del nacimiento de la ONU en España concretamente durante la II República, la mujer tenía plena capacidad de obrar. Sin embargo, tras el estallido de la Guerra Civil y la instauración de la Dictadura se produce un cambio radical, y durante el tiempo que dura la Dictadura la mujer queda 
subordinada al hombre, limitándose así la capacidad de obrar. Esto hace que, debido a los avances de la ONU, cuando España sale de este período los poderes públicos tienen dos objetivos concretos; modificar las leyes y concienciar a la sociedad de la igualdad de género para conseguir situar a España en la misma posición que el resto de países de la ONU.

Palabras claves: ONU, igualdad, dictadura, II República, género, conferencias.

\begin{abstract}
This work has focused on synthesizing the evolution of gender equality within the United Nations through several stages. Each stage outlines which of the UN's actions have been most instrumental in the fight against discrimination, while drawing comparisons to gender equality in Spain. Prior to the birth of the UN, Spanish women had full capacity to act, specifically during The Second Republic. However, this was not the case following the outbreak of The Civil War and the establishment of The Dictatorship. Radical changes occurred in Spanish society in these moments, resulting in women remaining subordinate to men and limiting their ability to act. As the UN continues to make advances, it is in Spain's best interest to move away from the aforementioned period and to place itself in the same position as the other UN countries. This can be achieved by focusing its public powers on two specific objectives: by modifying laws and raising awareness pertaining to gender equality.
\end{abstract}

Key words: UN, equality, dictatorship, II Republic, gender, conferences.

\title{
1. INTRODUCCIÓN
}

El Derecho a la Igualdad es un Derecho Humano Fundamental imprescindible para que los Estados consigan desarrollarse de forma democrática, tiene en cuenta 
distintos factores; etnia, raza, etcétera. Nosotros nos centraremos en la igualdad de género, analizando su evolución dentro de la Organización de Naciones Unidas ${ }^{101}$.

La ONU ha sido una clara defensora de la igualdad entre los hombres y las mujeres desde sus comienzos, uno de sus objetivos ha sido el empoderamiento de las mujeres ya que como ha manifestado "estimula la productividad y el crecimiento económico"102. Pero la evolución de la igualdad en España no se ha desarrollado al mismo ritmo, durante la Dictadura Franquista la mujer tenía un papel secundario y era considerada como un sujeto en el que dentro del matrimonio no tenía posibilidad de decidir acerca de la procreación, necesitando además "la autorización" del varón para la toma de decisiones. En efecto, esta situación hizo que España, tras salir de la Dictadura, tuviera que dar pasos acelerados tanto en el ámbito legislativo como en el pensamiento de la sociedad española.

El Derecho a la Igualdad en la ley y ante la ley junto con la prohibición de discriminación por razón de sexo ha sido recogido en una multitud de instrumentos internacionales, en muchas ocasiones insuficientes como así se ha podido demostrar posteriormente ${ }^{103}$. Esa evolución normativa comienza con la Carta Fundacional de la ONU, creada el 26 de junio de 1945 en San Francisco ${ }^{104}$ y entrando en vigor el 24 de octubre del mismo año, y que siguiendo a Carrillo Salcedo constituye el punto de arranque del proceso de internacionalización de los Derechos Humanos ${ }^{105}$. En el contexto de la ONU no solamente tenemos la Carta Fundacional sino, declaraciones, convenciones sobre Derechos Humanos y una cantidad de documentos emanados de Conferencias Mundiales que como señala Márquez

101 En adelante ONU.

102 Véase en https://www.un.org/es/sections/issues-depth/genderequality/\#: : :text=La\%20igualdad\%20de\%20g\%C3\%A9nero\%2C\%20adem\%C3\%A1 s,productividad\%20y\%20el\%20crecimiento\%20econ\%C3\%B3mico.

103 PECES-BARBA MARTíNEZ, G., Curso de derechos fundamentales. Teoría General, Universidad Carlos III de Madrid, Boletín Oficial del Estado, Madrid, 1995, p.181.

104 CARTA DE NACIONES UNIDAS, firmada el 26 de junio de 1945, entró en vigor el 24 de octubre de 1945.

105 CARRILLO SALCEDO, J. A., Soberanía del Estado y Derechos Humanos, Tecnos, Madrid, 1995, p. 23. 


\section{7 LA EVOLUCIÓN HISTÓRICA DE LA IGUALDAD DE GÉNERO}

Carrasco, presentan un fuerte contenido de los Derechos Humanos y reflejan específicamente derechos de la mujer ${ }^{106}$.

Por lo tanto, la finalidad de este artículo es indagar en la historia y recoger las manifestaciones más emblemáticas que la ONU ha realizado en lo relativo a la igualdad de género, comparándolo con la evolución en el ordenamiento jurídico español. Para ello hemos distinguido varias etapas en el proceso evolutivo y hemos analizado en cada una de las etapas lo que ocurría en ese momento en España.

\section{LA PRIMERA ETAPA: EL ALUMBRAMIENTO}

La primera etapa nace en 1945 coincidiendo con la creación de la ONU. La labor de las Naciones Unidas ha sido gradual, siendo una de las primeras manifestaciones que tenemos sobre la protección de las mujeres y el reconocimiento de la discriminación que éstas sufrían, se encuentra en la Carta Fundacional concretamente en el artículo 1 que señala que se "atendería a la situación de especial vulnerabilidad que sufrían las mujeres"107. Se reconoce así que las mujeres vienen sufriendo una situación de especial vulnerabilidad, sin embargo, no se recoge en ella un catálogo de Derechos Humanos.

En 1946, un año después al nacimiento de la ONU, se crea la Comisión de la Condición Jurídica y Social de la Mujer ${ }^{108}$, órgano internacional intergubernamental que se dedica a la promoción de la igualdad de género y empoderamiento de la mujer, dependiente del Consejo Económico y Social; su función es imprescindible para la promoción de los derechos de la mujer documentando la realidad que viven las mujeres en todo el mundo y elaborando normas internacionales sobre esta materia ${ }^{109}$.

\footnotetext{
106 MÁRQUEZ CARRASCO, C., "Los Derechos Humanos de las mujeres, la justicia penal internacional y la perspectiva de género, Investigación y género, avance en las distintas áreas de conocimiento", Idus, Sevilla, 2009, p. 719.

107 NUÑO, L., "Evolución del tratamiento de la igualdad de género en el ámbito internacional", Gaceta Sindical, Nueva Etapa, n. 12, Madrid, 2009, p. 161.

108 Resolución 11(II) del Consejo, de 21 de junio de 1946.

${ }^{109}$ Resolución 11(II) del Consejo, de 21 de junio de 1946.
}

Attribution-NonCommercial 4.0 International (CC BY-NC 4.0). e-ISSN: $2660-552 X$ 
La primera vez que se reunió la Comisión fue en Nueva York, en Lake Success, en febrero de 1947. Desde su creación, tuvo el apoyo de las Naciones Unidas, convirtiéndose en 1946 en la División para el Adelanto de la Mujer dependiente de la Secretaría de las Naciones Unidas. Se trata de un grupo dirigido a la defensa de la igualdad de género y el empoderamiento de la mujer, buscando promover el programa mundial sobre la igualdad de género y las cuestiones relativas a los Derechos Humanos de las mujeres, asegurándose que las opiniones de las mujeres sean escuchadas y que sus prioridades y preocupaciones se integren en todos los foros internacionales de política.

En 1951 la Comisión elaboró el Convenio 100110, llamado también de Igualdad de Remuneración entre la mano de obra masculina y la mano de obra femenina ante un trabajo de igual valor, consagrando así el principio de igualdad salarial entre hombres y mujeres. A dicho Convenio España no se adhiere hasta 1967, siendo hasta ese momento la norma vigente la Ley Fundamental de Fuero del trabajo de 1938, que nació como una Ley ordinaria convirtiéndose ocho años más tarde en Ley fundamental ${ }^{111}$.

Mientras que las Naciones Unidas en esta etapa tenía como uno de sus principales objetivos eliminar la desigualdad y situación de vulnerabilidad que venían sufriendo las mujeres en España, se encontraba vigente la Ley de contratos de $1944^{112}$ cuyas manifestaciones más relevantes eran: la prohibición de que las mujeres trabajaran por la noche, que recibieran el salario ellas si el marido de oponía, o incluso ser autorizadas por el marido para poder trabajar. En definitiva, la mujer era considerada un ser incapaz para dirigir su propia vida. Se fomentaba con la legislación vigente en ese momento que la mujer quedara relegada a un segundo plano, necesitando al marido para tomar las principales decisiones de su vida. EI

${ }^{110}$ C100 - Convenio sobre igualdad de remuneración, 1951 (no. 100).

${ }^{111}$ DOMÍNGUEZ MARTíN, R., y SÁNCHEZ-SÁNCHEZ, N., "Las diferencias salariales por género en España durante el desarrollismo franquista", Reis, №. 107, Madrid, 2007, p. 147.

${ }^{112}$ Decreto de 26 de enero de 1944 por el que se aprueba el texto refundido del Libro I de la Ley de Contrato de Trabajo. 
papel que jugaba la mujer en este momento era la de ama de casa, ser buena madre y mejor esposa.

Concluimos así que, en esta primera etapa, que va desde 1945 a 1949 y, a la que nosotros denominamos "la etapa del alumbramiento", se produce el nacimiento de las Naciones Unidas y con ella la búsqueda de la igualdad formal y material entre los hombres y las mujeres, promoviendo la elaboración de leyes internacionales y nacionales para acabar con las desigualdades especialmente en materia salarial y se trata también del momento en el que empiezan a florecer los convenios internacionales para la igualdad entre hombres y mujeres, mientras que en España la situación en este sentido, estaba más atrasada.

\section{LA SEGUNDA ETAPA: EL CRECIMIENTO}

En esta segunda etapa denominada la "etapa de crecimiento" abarca desde 1951 a 1974, momento en el que se adoptan las grandes convenciones que supondrán un hito fundamental para el desarrollo del Derecho a la lgualdad entre hombres y mujeres.

En 1953 se elabora uno de los primeros instrumentos internacionales de Derecho internacional, la Convención sobre los Derechos Políticos de la Mujer ${ }^{113}$. En esta Convención se reconoce que las mujeres tendrán "derecho a votar en todas las elecciones en igualdad de condiciones con los hombres sin discriminación alguna", así como el poder acceder a los cargos públicos y ejercer todas las funciones públicas establecidas por la legislación nacional en igualdad de condiciones pudiendo ocupar puestos elegibles y cargos en organismos públicos en igualdad de condiciones que los hombres. Cada uno de los artículos de la

113 CONVENCIÓN SOBRE LOS DERECHOS POLÍTICOS DE LA MUJER, abierta a la firma y ratificación el 31 de marzo de 1953 mediante Resolución 640 (VII), adoptada por la Asamblea General de las Naciones Unidas de 20 de diciembre de 1952, entrada en vigor: 7 de julio de 1954.

Attribution-NonCommercial 4.0 International (CC BY-NC 4.0). e-ISSN: 2660-552X 
Convención acaba con el inciso "en igualdad de condiciones con los hombres, sin discriminación alguna".

Posteriormente en 1957 y 1962 se elaboran dos convenciones más; la Convención sobre la Nacionalidad de la Mujer Casada ${ }^{114}$ y la Convención sobre el consentimiento para el Matrimonio, la Edad mínima para contraer matrimonio y el Registro de los matrimonios ${ }^{115}$.

La primera Convención entró en vigor el 29 de enero de 1958, siendo su principal objetivo el de acabar con los conflictos de leyes sobre la adquisición o pérdida de la nacionalidad que se producían, cuando la mujer contraía matrimonio o se disolvía. La Declaración Universal de Derechos Humanos reconoce que toda persona tiene derecho a una nacionalidad y a nadie se le puede privar arbitrariamente de la misma ni al cambio de nacionalidad, la celebración o disolución del matrimonio entre nacionales y extranjeros así cómo, que el cambio de la nacionalidad del marido no afecte a la nacionalidad de la esposa, ni el hecho de que uno de sus nacionales adquiera voluntariamente la nacionalidad del otro Estado o el que renuncie a la nacionalidad no impedirá que la mujer del cónyuge conserve la que posee.

La segunda Convención citada señala que muchos Estados seguían contemplando prácticas referentes al matrimonio y a la familia que son incompatibles con los principios de la Carta de las Naciones Unidas y la Declaración Universal de Derechos Humanos, por ello se establece que los cónyuges presten el consentimiento para contraer matrimonio de forma libre dándose la debida publicidad del mismo y celebrándose ante la autoridad competente y testigos que

\footnotetext{
114 CONVENCIÓN SOBRE LA NACIONALIDAD DE LA MUJER CASADA, abierta a la firma y ratificación por la Asamblea General en su resolución 1040 (XI), de 29 de enero de 1957.

115 CONVENCIÓN SOBRE EL CONSENTIMIENTO PARA EL MATRIMONIO, LA EDAD MÍNIMA PARA CONTRAER MATRIMONIO Y EL REGISTRO DE LOS MATRIMONIOS, abierta a la firma y ratificación por la Asamblea General en su resolución 1763 A (XVII), de 7 de noviembre de 1962.
} 
establezca la ley. Se elimina así la necesidad de que el padre de la futura esposa tenga que autorizar el matrimonio.

Por otro lado, en 1967 se aprueba a petición de la Asamblea General de las Naciones Unidas una Declaración sobre la eliminación de la discriminación de la mujer en la cual se recogía que la discriminación contra la mujer limita la igualdad con el hombre siendo injusta y constituyendo una ofensa a la dignidad humana. Se tendrán que adoptar todas las medidas apropiadas a fin de abolir las leyes, costumbres, reglamentos y prácticas que constituyen una discriminación hacia la mujer, siendo la finalidad de esta Convención, reconocer la igualdad de los hombres y mujeres ${ }^{116}$.

Por su parte, en España se estaban dando en esta etapa algunas reformas con el fin de eliminar ciertas situaciones discriminatorias. De esta forma se aprobó la Ley de 24 de abril de 1958 que modifica determinados artículos del Código Civil ${ }^{117}$. Se estableció que el marido para poder enajenar y obligar a título oneroso los bienes de la sociedad gananciales necesitaba el consentimiento de la mujer. Otro de los cambios es que la mujer que se propusiera a demandar la separación o nulidad de su matrimonio podía pedir que se la separara provisionalmente del marido confiándola con igual carácter a los hijos menores de siete años. Hasta ese momento, la mujer casada en el supuesto de separación era obligada a salir de casa y sólo podía llevarse consigo enseres como la cama, la ropa de uso diario; y a los hijos menores de tres años hasta la sentencia de separación, pues en ese momento si era culpable perdía a los hijos. Se reconoció también la posibilidad de que fuera tutora de los hijos, aunque necesitara la autorización del marido, y la tutela de los locos y sordomudos prefiriéndose siempre en este último caso al varón ${ }^{118}$.

\footnotetext{
${ }^{116}$ Resolución 2263 (XXII), de 7 de noviembre de 1967.

117 Ley de 24 de abril de 1958 por la que se modifican determinados artículos del Código civil, BOE n‥ 99, de 25 de abril de 1958.

118 MORAGA GARCÍA, M., "Notas sobre la situación jurídica de la mujer en el Franquismo", Feminismos, nº. 12, Madrid, 2008, p. 238.
}

Attribution-NonCommercial 4.0 International (CC BY-NC 4.0). e-ISSN: 2660-552X 
Tras unos años sin muchos avances entró en vigor la Ley de 4 de julio de 1970119 eliminando la posibilidad de que el hombre diera en adopción a los hijos sin el consentimiento de la madre. Dos años más tarde se fijó la mayoría de edad de la mujer a los 21 años, como la del hombre, pues hasta ese momento las mujeres no alcanzaban la mayoría de edad hasta los 25 años, debiendo permanecer en el hogar paterno hasta el momento de contraer matrimonio, consolidándose así un modelo de familia "como célula primaria, natural y fundamento de toda sociedad, correspondiéndole a la mujer el rol de esposa y madre, y por lo tanto, entre sus funciones se encontraba la de educar a los hijos en la fe cristiana y en la doctrina falangista, y ser el refugio y descanso del marido" 120.

En lo que refiere el Derecho de sufragio femenino, se reconoce en España por primera vez en la Constitución de 1931, sin embargo, poco durará este privilegio pues, tras la Guerra Civil y la llegada de la Dictadura este derecho queda abolido. Se suprimieron así muchos de los avances que las mujeres habían conseguido, y hasta 1977 no se volvió a recuperar.

En definitiva, esta etapa que finaliza en 1974 se caracteriza, por un lado, porque se celebran el mayor número de convenciones internacionales desde el nacimiento de las Naciones Unidas, y por otro lado porque se producen en España unos tímidos avances en lo relativo a la igualdad entre hombres y mujeres, aunque los logros más importantes llegarían después.

\section{LA TERCERA ETAPA: LA ERA DE LA MUJER}

Abordamos ahora la etapa denominada a nuestro parecer La Era de la mujer que comienza en el año 1975 y acaba en 1985. Hemos considerado denominarla así porque es la primera vez que se declara el Año Internacional y se crea la primera Conferencia sobre la mujer. Momento histórico que a su vez coincide con un cambio

${ }^{119}$ Ley $7 / 1970$, de 4 de julio, de modificación del capítulo $V$ del título VII del libro I del Código Civil, sobre adopción, BOE no. 161, de 7 de julio de 1970.

120 lbídem, p. 232. 
legislativo insólito en España: la entrada en vigor de la Constitución Española en el año 1978.

En el ámbito internacional se toma conciencia de la necesidad no sólo de crear leyes para luchar contra la discriminación de la mujer sino, de llevar a cabo acciones concretas $^{121}$. Así se declara 1975 como el Año Internacional de la Mujer ${ }^{122}$ y se celebra la Primera Conferencia Internacional en México sobre Mujeres y Desarrollo de las Naciones Unidas.

En esta Primera Conferencia se formularon las recomendaciones sobre las acciones y medidas que debían de ser adoptadas para conseguir la plena participación de la mujer en la vida económica, social, cultural y política. Los tres objetivos prioritarios eran: 1. La igualdad plena de género y la eliminación de la discriminación por motivos de género. 2. La plena participación de las mujeres en el desarrollo. 3. Una mayor contribución de las mujeres a la paz mundial. Y se aprueba además un plan de acción que marcaba las directrices a los gobiernos y a toda la comunidad internacional para los diez años siguientes, llamándose la Década de la Mujer. Las metas eran concretas, conseguir el acceso de la mujer a la educación, trabajo, participación política, salud, vivienda, planificación familiar y alimentación en igualdad de condiciones que los hombres.

En 1979 antes de la Segunda Conferencia se elabora la Convención sobre la eliminación de todas las formas de discriminación de la mujer (CEDAW) ${ }^{123}$ donde se pide la igualdad de la mujer con independencia del estado civil que tenga, tanto en la esfera política, económica, social cultural y civil. Reclama que se elaboren leyes por parte de los Estados que prohíban la discriminación y que se adopten

121 TERÁN VELASCO, M., "La transversalidad de género. Valoraciones a partir de algunos documentos de las Naciones Unidas", Anuario Español de Derecho Internacional, $\mathrm{n}$ ㅇ 31, Madrid, 2015, p. 329.

122 Resolución 3010 (XVII) de la Asamblea General de las Naciones Unidas fue una resolución adoptada el 18 de diciembre de 1972.

123 CONVENCIÓN SOBRE LA ELIMINACIÓN DE TODAS LAS FORMAS DE DISCRIMINACIÓN CONTRA LA MUJER, adoptada y abierta a la firma y ratificación, o adhesión, por la Asamblea General en su resolución 34/180, de 18 de diciembre de 1979.

Attribution-NonCommercial 4.0 International (CC BY-NC 4.0).

e-ISSN: 2660-552X 
medidas para acelerar la igualdad de hombres y mujeres. Se trata además del primer instrumento internacional que define la discriminación contra la mujer como “toda distinción, exclusión o restricción basada en el sexo, que tenga por objeto o por resultado menoscabar o anular el reconocimiento, goce o ejercicio por la mujer, independientemente de su estado civil, sobre la base de la igualdad del hombre y la mujer, de los derechos humanos y las libertades fundamentales en las esferas política, económica, social, cultural y civil o en cualquier otra esfera".

Posteriormente, en 1980 se lleva a cabo la Segunda Conferencia de Mujer y Desarrollo de las Naciones Unidas en Copenhague. Esta Conferencia viene marcada por la reflexión sobre el cumplimiento de las directrices que se habían marcado en la Primera Conferencia. La Conferencia se clausuró con un programa de acción y se evaluó cómo se había desarrollado los primeros años de la Década de la Mujer, concluyendo que había una falta de implicación y participación de los hombres en el proceso de igualdad, una voluntad política insuficiente por parte de los Estados, una falta de reconocimiento de la contribución de las mujeres en la sociedad, en los puestos de toma de decisiones, así como una escasez de servicios sociales de apoyo, falta de financiación y poca sensibilización entre las mujeres ${ }^{124}$.

La Tercera Conferencia Mundial sobre la Mujer celebró en Nairobi en 1985, coincidiendo con el fin de esta etapa, teniendo como eje principal evaluar y revisar la Década de la Mujer. Se elaboró un proyecto que recogía las estrategias futuras y se elaboraron las guías para poner en marcha la igualdad, apareciendo con fuerza, como señala Terán de Velasco, los conceptos de género y transversalidad ${ }^{125}$.

En definitiva, esta etapa se caracteriza porque supone un punto de inflexión en el papel de las mujeres, concretamente en España con dos momentos insólitos; la

\footnotetext{
124 Véase a SOLANAS, M., "Igualdad de género y política exterior española", Análisis del Real Instituto Elcano, no 21, Madrid, 2014.

125 Ibídem, p. 329.
} 
Ley de 2 de mayo de 1975 que modifica el Código Civil y el Código de Comercio ${ }^{126}$, y la entrada en vigor de la Constitución Española en el año 1978.

Con la Ley de 2 de mayo de 1975 se responde a diferentes problemas que venían sufriendo las mujeres en lo referente a su capacidad de obrar, pues, se elimina por un lado que el matrimonio no modifique la nacionalidad de los cónyuges ni limite ni condicione su adquisición o recuperación, así como que ninguno de los cónyuges ostentará la representación del otro, algo que venía ocurría hasta ese momento pues el hombre ostentaba la representación de la mujer para actos tan relevantes como la firma de contratos laborales. Por otro lado, desaparece la incapacidad de la mujer casada para ser tutora de sus hijos y para aceptar herencias, así como la capacidad para administrar los bienes del matrimonio al igual que el marido.

En el año 1976 entró en vigor la ley de Relaciones Laborales ${ }^{127}$ y en ella se concede a la mujer trabajadora un período de descanso de seis semanas antes del parto y ocho semanas después del parto. También en esta misma ley se concede a la mujer casada -también al marido- la posibilidad de que, en el caso de que el marido sea trasladado de domicilio, ésta pueda también pedir traslado si en su empresa hay sucursales en ese domicilio.

En 1977 antes de la aprobación de la Constitución se aprobaron los Pactos de la Moncloa, en el que se estableció la reforma del código penal para despenalizar el adulterio y el amancebamiento, la despenalización y la regulación de la venta de anticonceptivos, la modificación de las edades de la mujer tomadas en consideración para la tipificación del rapto y del estupro. Se incluyó también la no discriminación de los hijos por razón del estado civil de la madre puesto que éstos se consideraban hijos ilegítimos en el Registro Civil hasta este momento.

126 Ley 14/1975, de 2 de mayo, sobre reforma de determinados artículos del Código Civil y del Código de Comercio sobre la situación jurídica de la mujer casada y los derechos y deberes de los cónyuges, BOE ํ‥ 107, de 5 de mayo de 1975

127 Ley 16/1976, de 8 de abril, de Relaciones Laborales, BOE no. 96, de 21 de abril de 1976.

Attribution-NonCommercial 4.0 International (CC BY-NC 4.0).

e-ISSN: 2660-552X 
Ya en el año 1978 con la entrada en vigor de la Constitución Española se reconoce el Derecho de Igualdad en el artículo 14, así como la posibilidad de que los poderes públicos eliminen los obstáculos que impidan conseguir la igualdad, es decir, la discriminación positiva. A partir de este momento, se pone en marcha una gran cantidad de mecanismos para eliminar la discriminación y la situación que venían sufriendo las mujeres.

Más tarde en 1981 se aprobó la Ley del Divorcio y la reforma del Código Civil ${ }^{128}$, una reforma importantísima para las mujeres ya que se puso a la mujer en pie de igualdad respecto del marido para la administración y disposición de los bienes gananciales. Así pues, en esta etapa la mujer adquiere la plena capacidad de obrar, aunque todavía quedaba mucho por hacer, concretamente en materia de violencia sobre la mujer. La igualdad de sexos en España arrancó con retraso con respecto a las Naciones Unidas, pero se ha conseguido equiparar.

\section{CUARTA ETAPA: LA LUCHA CONTRA LA VIOLENCIA SOBRE LA MUJER}

Esta etapa comienza en 1986 y llega a nuestros días, viene marcada por los esfuerzos de los Estados y de la ONU de eliminar las situaciones de violencia contra la mujer. En 1987 la Comisión consiguió elevar las cuestiones de género a la categoría de temas transversales, contribuyendo de esta forma a conseguir que el problema de la violencia contra las mujeres figurara como uno de los temas principales a tratar en los debates internacionales, culminando con la Declaración sobre la eliminación de la violencia contra la mujer, aprobada por la Asamblea General el 20 de diciembre de 1993.

\footnotetext{
128 Ley 30/1981, de 7 de julio, por la que se modifica la regulación del matrimonio en el Código Civil y se determina el procedimiento a seguir en las causas de nulidad, separación y divorcio, BOE №. 172, de 20 de julio de 1981.
} 


\section{7}

Un año más tarde se nombró una Relatora especial sobre la violencia contra la mujer, sus causas y consecuencias, y tenía como función principal investigar e informar sobre la violencia contra las mujeres.

En esta Declaración se define la violencia contra la mujer como "todo acto de violencia basado en la pertenencia al sexo femenino que tenga o pueda tener como resultado un daño o sufrimiento físico, sexual o sicológico para la mujer, así como las amenazas de tales actos, la coacción o la privación arbitraria de la libertad, tanto si se producen en la vida pública como en la vida privada" ${ }^{129}$. Esta definición presenta una peculiaridad y es, que esta violencia no se limita a la violencia que se ejerce en el seno de las relaciones sentimentales presentes o pasadas, sino que considera violencia contra la mujer, toda violencia que las mujeres sufran tanto en la esfera pública como privada, aunque entre ella y el agresor no exista una relación sentimental.

El 25 de junio de 1993 se aprueba por consenso de 171 Estados la Declaración y Programa de Acción de Viena de la Conferencia Mundial de Derechos Humanos, fruto de la solicitud que realizó la Asamblea General en 1989 para que se celebrara una reunión mundial dónde se examinaran y evaluaran los progresos logrados en la esfera de los Derechos Humanos desde la aprobación de la Declaración Universal de Derechos Humanos.

Un año más tarde, la Comisión de Derechos Humanos adoptó la resolución 1994/45 en el que se reafirmaron los principios que habían evolucionado durante los 45 años anteriores y se fortalecieron las bases para los nuevos progresos en la esfera de los Derechos Humanos centrándose especialmente en promover la protección de los derechos de las mujeres, de los niños y el de los pueblos indígenas. Se apoyó también la creación de un Relator Especial sobre la violencia contra la mujer, así como se recomendó a la Asamblea General que proclamara un decenio internacional sobre los pueblos indígenas del mundo y se hizo un

${ }^{129}$ Declaración sobre la eliminación de la violencia contra la mujer.

Attribution-NonCommercial 4.0 International (CC BY-NC 4.0). e-ISSN: 2660-552X 
llamamiento a la ratificación universal de la Convención sobre los Derechos del Niño para el año 1995.

Otro momento de gran importancia lo tuvo la Conferencia Internacional sobre Población y Desarrollo celebrada en El Cairo en 1994. Los delegados que acudieron a ella convinieron que, la igualdad y el empoderamiento de las mujeres es una prioridad mundial, enfocándolo no solo desde la perspectiva de los Derechos Humanos universales sino también como una forma de erradicar la pobreza y la estabilización del crecimiento de la población.

El 13 de septiembre de 1994, fruto de la Conferencia se aprobó un Programa de acción en el que se apoyó una nueva estrategia centrándose en dar soluciones a las necesidades de los hombres y las mujeres, empoderando a las mujeres y fomentando que se dieran más opciones a las mujeres para el acceso a la educación y servicios sanitarios, así como una participación total en la política y en los procesos de toma de decisiones. La pieza clave de esta Conferencia es el fortalecer a las mujeres para mejorar la calidad de vida de todas las personas ${ }^{130}$.

En la Cuarta Conferencia Mundial sobre la mujer celebrada en Pekín en $1995^{131}$ se aprobó la Declaración y Plataforma de Acción de Beijing, y se creó tal como reclamaba la Plataforma una nueva oficina de las Naciones Unidas para la promoción de la igualdad de género, llamada la Oficina del Asesor Especial en Cuestiones de Género y Adelanto de la Mujer. Esta Cuarta Conferencia fue algo más allá que la de Nairobi, y demandó la necesidad de que los derechos de las mujeres fueran considerados derechos humanos. Se centró el documento final en doce áreas críticas, que suponían un obstáculo para conseguir el adelanto de la

130 RIVERO MÉNDEZ, I., "Las cuatro conferencias mundiales de la ONU sobre la mujer relato testimonial",

Agentes de igualdad de oportunidades: acciones positivas en el marco de la cooperación, por Rosa María MARTíNEZ SEGARRA, Celia María PARCERO TORRE, Miren Josune AGUINAGA ROUSTAN, Universitas Internacional, Madrid, 2006, pp. 5366.

Idioma: español

131 ARTEAGA ANSA, T., "¿Qué ha supuesto la Conferencia de Pekín para las mujeres?", Emakunde, País Vasco, 1998, pp. 3-32. 
mujer, exigiéndose a los gobiernos que adoptaran medidas para acabar con la pobreza, educación y capacitación, salud, violencia, conflictos armados, economía, participación en el poder de las mujeres y en la toma de decisiones y mecanismos institucionales para el adelanto de la mujer, derechos humanos, medio ambiente y la niña ${ }^{132}$.

Así, a partir de este momento se introduce la perspectiva de género, esto es, que los gobiernos tenían que analizar cuando tomaran decisiones o planes, los efectos que éstos iban a tener en las mujeres y en los hombres así, como en sus necesidades.

Las conclusiones del Consejo Económico y Social (ECOSEC) de 1997 definieron la perspectiva de género cómo: "el proceso de evaluación de las consecuencias para las mujeres y los hombres de cualquier actividad planificada, inclusive las leyes, políticas o programas, en todos los sectores y a todos los niveles. Es una estrategia destinada a hacer que las preocupaciones y experiencias de las mujeres, así como de los hombres, sean un elemento integrante de la elaboración, la aplicación, la supervisión y la evaluación de las políticas y los programas en todas las esferas políticas, económicas y sociales, a fin de que las mujeres y los hombres se beneficien por igual y se impida que se perpetúe la desigualdad. El objetivo final es lograr la igualdad [sustantiva] entre los géneros".

En el año 2000 se elaboran Los Objetivos de Desarrollo del Milenio de las Naciones Unidas, entre los cuales, se encuentra la "Igualdad de Género", y cinco años más tardes aprovechando el décimo aniversario de la Conferencia de Pekín la CSW organizó la sesión de revisión llamada, Beijing +10.

Dos años más tarde entró en vigor el Tratado de Roma para la Corte Penal Internacional la cual se había elaborado en 1996. Se trata del primer tratado en el que se reconocen una serie de actos de violencia sexual y violencia de género entre

132 TERÁN VELASCO, M., "La transversalidad de género. Valoraciones a partir de algunos documentos de las Naciones Unidas", Óp.cit., p. 334.

Attribution-NonCommercial 4.0 International (CC BY-NC 4.0). e-ISSN: 2660-552X 
los crímenes más graves de trascendencia internacional ${ }^{133}$ y se da una de las primeras definiciones del concepto de "género". Así, gracias al Tratado se tipifica tales delitos como crímenes internacionales, se incorpora la perspectiva de género y el concepto de género por primera vez, se regula unas normas especiales para el procedimiento y la prueba de las víctimas y testigos de la violencia sexual.

Unos años más tarde, concretamente el 2 de julio de 2010 se creó por la Asamblea General de las Naciones Unidas un organismo encargado de impulsar más rápidamente el progreso sobre la igualdad de género y empoderamiento de la mujer: ONU Mujeres. Se fusionaron cuatro instituciones y organismos internaciones: el Fondo de Desarrollo de las Naciones Unidas para la Mujer, la División para el Adelanto de la Mujer, la Oficina del Asesor Especial en Cuestiones de Género y el Instituto Internacional de Investigaciones y Capacitación para la Promoción de la Mujer.

Una de las últimas acciones de la ONU ha sido la Iniciativa Spotlight, que nace en septiembre de 2017, y donde la ONU y la Unión Europea se unen para llevar a cabo una campaña orientada a eliminar todas las formas de violencia contra las mujeres y las niñas.

Por su parte, en esta etapa España comienza anotar un fuerte cambio social, tras haber salido de una etapa en la que la mujer tenía una posición muy poco relevante en la sociedad, como ya vimos en la etapa anterior, se empiezan a llevar a cabo unas pinceladas de cambios. Concretamente en este período se empiezan a notar pequeños progresos para acabar con un problema que la sociedad venía sufriendo desde ya hacía años, la violencia contra la mujer.

El inconveniente con el que jugaba España era que, durante la etapa de la Dictadura, la violencia que se producía en el seno de la familia se ocultaba, y se consideraba por los poderes públicos un problema que debía de resolverse en el ámbito familiar. Pero gracias a las influencias internacionales y a la instauración de

133 MOREYRA, M. J., "La Perspectiva de género: la importancia de la Corte Penal Internacional”, Relaciones Internacionales, Costa Rica, no 28, 2005, p. 93. 


\section{1 LA EVOLUCIÓN HISTÓRICA DE LA IGUALDAD DE GÉNERO}

una Democracia, esta situación empieza a cambiar, aunque cuando se reguló la violencia contra la mujer de forma separada a la violencia doméstica fue en el año 2004. El Código Penal en España reguló por primera vez los malos tratos y la violencia física dentro del domicilio conyugal con la Ley Orgánica 3/1989, de 21 de junio, concretamente en el artículo 539, tipificándose la violencia habitual diferenciándola del delito de lesiones. A partir de este momento empiezan una serie de reformas penales enfocadas a castigar la violencia machista.

Durante la etapa de la Dictadura, la violencia machista existía, pero se ocultaba, de forma que gracias a la Democracia y a las influencias internacionales se empieza a tomar conciencia por parte de la sociedad de un grave problema que había que atacar. En el año 1995 aprueba el nuevo Código Penal y el delito de violencia habitual pasa a regularse en el artículo 153, incrementándose la pena.

Posteriormente, cuatro años después se aprueba la Ley Orgánica 14/1999, de 19 de junio, modificadora del Código Penal y de la Ley de Enjuiciamiento Criminal. Se introduce la violencia psíquica en el ámbito familiar y se amplía el círculo de sujetos activos y pasivos incluyendo las relaciones matrimoniales o de hecho que hubieran existido en el pasado.

Los años 2003 y 2004 fueron decisivos. Concretamente en el año 2003 entra en vigor la Ley Orgánica 11/2003, de 29 de septiembre, que versa sobre las medidas concretas en materia de seguridad ciudadana, violencia doméstica e integración social de los extranjeros; y la Ley Orgánica 15/2003, de 25 de noviembre, por la que se modifica la Ley Orgánica 10/1995, de 23 de noviembre, del Código Penal.

Por otra parte, en el año 2004 se elabora la Ley Orgánica 1/2004, de 28 de diciembre, de Medidas de Protección Integral contra la violencia de género.

Sin embargo, a diferencia de lo que establecía la Declaración para la eliminación de la violencia contra la mujer, la violencia de género era considerada como aquella violencia que se ejercía sobre una mujer, por parte de un hombre, dentro de una relación sentimental, presente o pasada, excluyendo aquella violencia que se 
produjese en cualquier otro ámbito. Que a nuestro parecer es un grave error, porque España no está cumpliendo con los objetivos de la Declaración.

Por último, en el año 2007 se aprobó la Ley Orgánica 3/2007134, de 22 de marzo, para la igualdad efectiva de mujeres y hombres, siendo un gran paso para España, pues se estableció por primera vez las estrategias de prevención y corrección para la discriminación por razón de sexo y el acoso laboral, y se implantó la necesidad de aplicar el principio de igualdad de forma transversal.

\section{CONCLUSIÓN}

Como señalaba al comienzo del trabajo, el objetivo era realizar un análisis evolutivo de cómo se ha ido desarrollando la igualdad entre hombres y mujeres, en el plano internacional y ver si el ritmo ha sido el mismo en España.

De esta forma, la evolución de la igualdad de sexos no ha evolucionado de la misma manera en los dos planos. Antes del nacimiento de la ONU en España la mujer tenía un papel muy importante durante la II República. De hecho, ocupaba puestos en los órganos de gobierno y tenía plena capacidad de obrar. Sin embargo, en 1939 y tras la Guerra Civil el papel de la mujer cambia por completo, queda relegada a un ámbito estrictamente doméstico y su capacidad de obrar, tal como hemos visto, se ve limitada.

Paralelamente en el ámbito internacional nace la ONU y comienzan una serie de cambios importantísimos, promoviendo que los Estados adopten las medidas necesarias para eliminar dicha desigualdad. Sin embargo, la situación en España da un vuelco radical cuando entra en vigor la Constitución Española, y la labor de los poderes públicos es fundamental para conseguir el cambio, pues no sólo tenían

134 Ley Orgánica 3/2007, de 22 de marzo, para la igualdad efectiva de mujeres y hombres, BOE no. 71, de 23 de marzo de 2007. 


\section{3 LA EVOLUCIÓN HISTÓRICA DE LA IGUALDAD DE GÉNERO}

que modificar las leyes sino también concienciar a la sociedad de la necesidad de luchar por la igualdad de $\operatorname{sexos}^{135}$.

En definitiva, la evolución en los dos planos, internacional y nacional, no ha sido al mismo ritmo, aunque actualmente en España el avance es imparable y la presencia de la mujer en el mercado laboral, y en los órganos de gobierno y responsabilidad es mayor. En este cambio ha tenido mucho que ver las influencias de la ONU. De hecho, España es uno de los países con una de las mejores valoraciones en lo que representa la igualdad de género, y ha trabajado con ONU Mujeres para contribuir a la internacionalización de la igualdad de género. Aunque desde nuestra perspectiva, creemos que en España es necesario realizar una revisión de la Ley Orgánica 1/2004 sobre el concepto de violencia de género ${ }^{136}$ y adaptarlo a la Declaración sobre la eliminación de la violencia contra la mujer, tal como afirmamos anteriormente.

La ONU, aunque va en buena dirección, tiene todavía que seguir trabajando para conseguir que esa igualdad se haga efectiva en todos los países, todavía, a día de hoy, las mujeres de todo el mundo dedican una media de tres veces de horas más al día de trabajo doméstico y de cuidados no remunerados que los hombres. Según los últimos datos, sólo el $47 \%$ de las mujeres en edad de trabajar, participaron en 2020 en el mercado laboral, frente al 74\% de los hombres. En los países como África y Asia occidental la situación es más preocupante ya que sólo es el $30 \%$ de mujeres son las que se encuentran en el mercado laboral ${ }^{137}$.

\footnotetext{
135 Véase a ALBERDI, I., "Temas y desafíos de la igualdad entre los géneros el liderazgo de las Naciones Unidas", Pensamiento Iberoamericano, no9, Madrid, 2011, pp. 263-280.

${ }^{136}$ Ley Orgánica 1/2004, de 28 de diciembre, de Medidas de Protección Integral contra la Violencia de Género, BOE, n․ 313, de 29 de diciembre de 2004. ${ }^{137}$ https://news.un.org/es/story/2020/10/1482722
} 


\section{BIBLIOGRAFÍA}

ALBERDI, I., (2011). "Temas y desafíos de la igualdad entre los géneros el liderazgo de las Naciones Unidas", Pensamiento Iberoamericano, $n^{\circ}$ 9, Madrid.

ARTEAGA ANSA, T., (1995). “¿Qué ha supuesto la Conferencia de Pekín para las mujeres?”, Emakunde, País Vasco.

CARRILlO SALCEDO, J. A. (1995). Soberanía del Estado y Derechos Humanos, Tecnos, Madrid.

DOMÍNGUEZ MARTíN, R. y SÁNCHEZ-SÁNCHEZ, N. (2007). "Las diferencias salariales por género en España durante el desarrollismo franquista", Reis, ํo. 107, Cantabria.

MÁRQUEZ CARRASCO, C. (2009). "Los Derechos Humanos de las mujeres, la justicia penal internacional y la perspectiva de género, Investigación y género, avance en las distintas áreas de conocimiento", Idus, Sevilla.

MORAGA GARCÍA, M. (2008). "Notas sobre la situación jurídica de la mujer en el Franquismo", Feminismos, №. 12, Madrid.

MOREYRA, M. J. (2005). "Perspectiva de género: la importancia de la Corte Penal Internacional”. Relaciones Internacionales, vol. 14, no 28.

NUÑO, L. (2009). "Evolución del tratamiento de la igualdad de género en el ámbito internacional”, Gaceta Sindical, ㄲo12.

PECES-BARBA MARTÍNEZ, G. (1995). Curso de derechos fundamentales. Teoría General, Madrid, Universidad Carlos III de Madrid, Boletín Oficial del Estado.

RIVERO MÉNDEZ, I., (2006). "Las cuatro conferencias mundiales de la ONU sobre la mujer relato testimonial", Agentes de igualdad de oportunidades: acciones positivas en el marco de la cooperación, por Rosa María MARTínEZ SEGARRA, Celia María 


\section{5 LA EVOLUCIÓN HISTÓRICA DE LA IGUALDAD DE GÉNERO}

PARCERO TORRE, Miren Josune AGUINAGA ROUSTAN, Universitas Internacional, Madrid.

TERÁN VELASCO, M. (2015). "La transversalidad de género. Valoraciones a partir de algunos documentos de las Naciones Unidas", Anuario Español de Derecho Internacional.

SOLANAS, M., (2014). "Igualdad de género y política exterior española", Análisis del Real Instituto Elcano, № 21, Madrid, 2014 